\title{
Osthole inhibits triple negative breast cancer cells by suppressing STAT3
}

\author{
Xuanxuan Dai ${ }^{1,2+}$, Changtian Yin ${ }^{1,2+}$, Yi Zhang $^{3}$, Guilong Guo ${ }^{2}$, Chengguang Zhao ${ }^{1}$, Ouchen Wang ${ }^{2}$, \\ Youqun Xiang ${ }^{2}$, Xiaohua Zhang ${ }^{2^{*}}$ and Guang Liang ${ }^{1^{*}}$
}

\begin{abstract}
Background: Triple-negative breast cancer (TNBC) is an aggressive subgroup of human breast cancer. Patients with TNBC have poor clinical outcome as they are non-responsive to current targeted therapies. There is an urgent need to identify new therapeutic targets and develop more effective treatment options for TNBC patients. Osthole, a natural product from C. monnieri, has been shown to inhibit certain cancer cells. However, the mechanisms of action as well as its effect on TNBC cells are not currently known.

Methods: We investigated the effect of osthole in cultured TNBC cells as well as in a xenograft model of TNBC growth. We also used a high-throughput proteomics platform to identify the direct binding protein of osthole.

Results: We found that osthole inhibited the growth of a panel of TNBC cells and induced apoptosis in both cultured cells and TNBC xenografts. We used a high-throughput proteomics platform and identified signal transducer and activator of transcription 3 (STAT3) as a potential binding protein of osthole. We further show that osthole suppressed STAT3 in TNBC cells to inhibit growth and induce apoptosis. Overexpressing STAT3 in TNBC reduced the effectiveness of osthole treatment.
\end{abstract}

Conclusions: These results provide support for osthole as a potential new therapeutic agent for the management of TNBC. Moreover, our results indicate that STAT3 may be targeted for the development of novel anti-TNBC drugs.

Keywords: Osthole, STAT3, Triple-negative breast cancer, Cell apoptosis, Xenografts

\section{Background}

Triple-negative breast cancer (TNBC) is a unique subset of human breast cancer that is characterized by negative estrogen receptor (ER), progesterone receptor (PR) and human epidermal growth factor receptor 2 (HER2) status. TNBC accounts for approximately $15-20 \%$ of all breast cancer diagnosis [1]. TNBC is far more aggressive and shows higher rates of relapse compared to other types of breast cancer [2]. Tumor heterogeneity and lack of effective molecular targets contributes to the poor prognosis $[3,4]$. Chemotherapy is currently the mainstay of treatment for patients with TNBC. Although chemotherapy is effective in a subgroup of these cancers, it fails

\footnotetext{
* Correspondence: xiaohuazhang2015@sina.com; wzmcliangguang@163.com ${ }^{+}$Xuanxuan Dai and Changtian Yin contributed equally to this work. ${ }^{2}$ Department of Surgical Oncology, the First Affiliated Hospital of Wenzhou Medical University, Wenzhou 325035, Zhejiang, China

${ }^{1}$ Chemical Biology Research Center, School of Pharmaceutical Sciences, Wenzhou Medical University, Wenzhou 325035, Zhejiang, China Full list of author information is available at the end of the article
}

in the majority of patients $[5,6]$. Hence, there is an urgent clinical need to discover new molecular targets and develop drugs with minimal toxicity to treat patients with TNBC.

Osthole (7-methoxy-8-isopentenoxycoumarin) is a coumarin-derivative extract of $C$. monnieri that has been shown to inhibit many pathological disorders. These include conditions such as allergies and inflammation [7], diabetes [8], as well as liver injury [9]. In addition, osthole has been reported to beneficial inhibitory effects in multiple types of cancer, including hepatic carcinomas [10], leukemia [11], gastric cancer [12], and lung cancer [13]. Specifically in breast cancer cells, osthole inhibits the growth of breast cancer cells, at least in culture [14, 15]. Taken together, the numerous studies conducted to date suggest that osthol possesses the potential to act in an inhibitory role in the progression of malignancies. However, the mechanisms of function and overall cellular effect of osthol toward particular cancers may not be the same. 
The mechanisms of action as well as its effect on TNBC cells are not currently known.

Here, we have investigated the effect of osthole in cultured TNBC cells as well as in a xenograft model of TNBC growth. We show that osthole inhibits the growth of TNBC cells and induces apoptosis. Using a high-throughput proteomis platform, we report for the first time, that osthole induces apoptosis in TNBC cells through the inactivation of signal transducer and activator of transcription-3 (STAT3) signaling pathway. In addition, osthole inhibited TNBC cell proliferation in mice implanted with TNBC cells. Our findings show that osthole is a therapeutic candidate in the treatment of patients with TNBC. We have also discovered a novel mechanism of the anti-cancer activities of osthole.

\section{Methods}

\section{Reagents}

Osthole (purity $>99 \%$ ) and biotin were purchased from the Aladdin Chemicals (China) and was dissolved in DMSO. Biotinylated-osthole (purity $>97.8 \%$ ) was designed and synthesized by Bocong Biotech (Guangzhou, China). Antibodies against cleaved-PARP (sc-56,196), Bax (sc-493), Bcl-2 (sc-492), Bcl-xl (sc-8392), MDM-2 (sc-965), CyclinB1 (sc-245), CDC2 (sc-54), Ki67 (sc-7846), GAPDH (sc-32,233), horseradish peroxidase (HRP)-conjugated goat anti-mouse IgG, HRP-conjugated donkey anti-rabbit IgG, and PE-conjugated secondary antibodies were purchased from Santa Cruz Biotechnology (Santa Cruz, CA). Antibodies against Phospho-STAT3 (Tyr705, Clone D3A7, 9145), STAT3 (12640S), and cleaved-caspase3 (9661S) were purchased from Cell Signaling Technology (Danvers, MA, USA). Fluorescein isothiocyanate (FITC) Annexin V Apoptosis Detection Kit I and Propidium Iodide (PI) were purchased from BD Pharmingen (Franklin Lakes, NJ).

\section{Cells culture}

Human breast cancer cell lines (MDA-MB-231, BT-549, MDA-MB-468, and MCF-7 were purchased from the Institute of Biochemistry and Cell Biology, Chinese Academy of Sciences (Shanghai, China). MDA-MB-231 and MCF-7 cells were cultured in DMEM medium (Gibco, Eggenstein, Germany), BT-549 cells were cultured in RPMI-1640 medium (Gibco), and MDA-MB-468 were grown in L15 medium (Gibco). Media in all cases was supplemented with $10 \%$ heat-inactivated fetal bovine serum (Hyclone, Logan, UT), 100 units/ mL penicillin, and $100 \mu \mathrm{g} / \mathrm{mL}$ streptomycin.

\section{Cell viability assay}

Human breast cancer cells were seeded in 96-well tissue culture plates at a density of 8000 per well, and allowed to attach overnight in complete growth media. Osthole were dissolved in DMSO and then diluted in medium to the desired final concentration $(6.25,12.5,25,50,100,200,400$, and $800 \mu \mathrm{M})$. The following day, cells were treated with osthole at increasing concentrations for $24 \mathrm{~h}, 48 \mathrm{~h}$, or $72 \mathrm{~h}$, respectively. Cell viability was then measured through MTT assay.

\section{Apoptosis and cell cycle analysis}

Cells were plated in $60-\mathrm{mm}$ dishes and allowed to attach overnight. Cells were then treated with osthole at 100, 150 , or $200 \mu \mathrm{M}$. Following treatments, cells were fixed then labeled with FITC-conjugated Annexin V/PI (for apoptosis detection) or PI staining (for cell cycle detection). Analyses were performed using FACSCalibur flow cytometer. Data for apoptosis and cell cycle distribution was analyzed using FlowJo7.6 software.

To assess morphological changes associated with apoptosis, we stained cells with Hoechst 33258 (Beyotime Biotechnology, China). Cells were challenged with osthole at 100,150 , or $200 \mu \mathrm{M}$ for 24 or $48 \mathrm{~h}$. Cells were then fixed with $4 \%$ formaldehyde solution and stained with Hoechst 33258. Images were captured using a fluorescence microscope (Nikon, Japan). Five microscopic fields were randomly selected from each treatment group.

\section{Western blot analysis}

TNBC cells and tumor tissues were lysed and protein concentrations were measured by the Bradford assay (Bio-Rad, Hercules, CA). Proteins were separated by sodium dodecyl sulfate-polyacrylamide gel electrophoresis and electro-transferred to poly-vinylidene difluoride transfer membranes. Membranes were blocked for $1.5 \mathrm{~h}$ at room temperature using fresh $5 \%$ nonfat milk in TBST. Primary antibody incubations were carried out overnight at $4{ }^{\circ} \mathrm{C}$. HRP-conjugated secondary antibodies were added for $1 \mathrm{~h}$, and the bands were visualized by using ECL substrate (Bio-Rad). Densitometric measurements were performed using Image $\mathrm{J}$ (National Institute of Health, MD).

The cytoplasmic and nuclear extracts were prepared by using KeyGen biotech Nuclear and Cytoplasmic Extraction Reagent kit (Nanjing, China). Cells were washed with ice cold PBS, collected and mixed with Buffer A and Buffer B. The mixture was centrifuged for $10 \mathrm{~min}$ at $3000 \mathrm{xg}$ at $4{ }^{\circ} \mathrm{C}$. Supernatant was collected as cytosolic extract. Buffer $\mathrm{C}$ was added to the pellets for $1 \mathrm{~h}$. Samples were then centrifuged at $14,000 \times \mathrm{g}$ for $30 \mathrm{~min}$ to extract nuclear proteins. Protein concentrations by measured by the Bradford assay.

\section{Proteome microarray assay and data analysis}

Arrayit HuProt ${ }^{\mathrm{tw}}$ v2.0 $19 \mathrm{~K}$ Human Proteome Microarrays (CDI Laboratories, Baltimore, MD) were blocked with 3\% BSA for $1 \mathrm{~h}$ at room temperature. Biotinylated-osthole was diluted to $10 \mu \mathrm{M}$ in blocking buffer and incubated on the proteome microarray for $1 \mathrm{~h}$ at room temperature. The arrays were washed with PBST and incubated with 
Cy3-Streptavidin at 1:1000 dilution (Sigma-Aldrich) for 1 $\mathrm{h}$ at room temperature. Finally, the microarray was spun dry and scanned with a GenePix 4200A microarray scanner (Molecular Devices, San Jose, CA). Data were analyzed by GenePix Pro 6.0 software. The signal to noise ratio (SNR) was defined as the ratio of median foreground value minus median background value. A cutoff was of $\mathrm{SNR} \geq 1.1$ was set.

\section{Immunofluorescence staining}

Cells were seeded in 35-mm cell culture dishes with glass bottom (NEST, Wuxi, China). After overnight culture in complete media, cells were serum-starved for $24 \mathrm{~h}$. Cells were then treated with osthole for $32 \mathrm{~h}$, followed by stimulation by $50 \mathrm{ng} / \mathrm{mL}$ IL-6 for $30 \mathrm{~min}$. Cells were fixed in $4 \%$ paraformaldehyde/0.1\% Triton-X100 solution. Primary anti-p-STAT3 antibody was added and samples incubated at $4{ }^{\circ} \mathrm{C}$ overnight. PE-conjugated goat anti-rabbit secondary antibody (1:200) was then added for $1 \mathrm{~h}$. Cells were counterstained with DAPI. Images were captured using a fluorescence microscopy (Nikon, Japan).

\section{Cell transfections}

Cells were transfected with expression-ready pCMV3 vector encoding STAT3 (HG10034-CF, Sino Biological, Beijing, China). To express STAT3, MDA-MB-231 cells were seeded at $6 \times 10^{5}$ cells per dish into $60 \mathrm{~mm}$ plates. DMEM medium without antibiotics was added and cells were allowed to grow to $50-70 \%$ confluence. The medium was then changed to freshly prepared Opti-MEM medium. Four $\mu \mathrm{g}$ of STAT3 plasmid or control plasmid was dissolved in $6 \mu \mathrm{L}$ Lipofectamine 2000 reagent and added onto cells. After $6 \mathrm{~h}$, the medium was replaced with complete media containing 10\% FBS. P-STAT3 and STAT3 expression in MDA-MB-231 cells was confirmed by Western blotting analysis after $48 \mathrm{~h}$.

\section{Breast cancer xenografts}

All animal studies were in compliance with the Wenzhou Medical University's Policy on the Care and Use of Laboratory Animals. Protocols for animal studies were approved by the Wenzhou Medical College Animal Policy and Welfare Committee. Five-week-old athymic BALB/c $\mathrm{nu} / \mathrm{nu}$ female mice (18-22 g) were purchased from Vital River Laboratories (Beijing, China). Animals were housed at a constant room temperature with a $12 \mathrm{~h}: 12 \mathrm{~h}$ light/dark cycle and fed a standard rodent diet and given water ad lib. The mice were divided into three experimental groups with six mice in each group. MDA-MB-231 cells were injected subcutaneously into the right flank at $5 \times 10^{6}$ cells in $100 \mu \mathrm{L}$ of PBS per mouse. When tumors reached a volume of $50-150 \mathrm{~mm}^{3}$, mice were treated with osthole by intraperitoneal injections twice daily (100 or $200 \mathrm{mg} / \mathrm{kg} /$ d). Osthole was dissolved in 6\% castor oil. Tumor volumes were determined by measuring length (l) and width (w) and calculating volume $\left(\mathrm{V}=0.5 \times 1 \times \mathrm{w}^{2}\right)$ at the indicated time points. At the end of the study, mice were sacrificed and the tumors were removed. Heart, kidney, and liver tissues were also harvested to assess any toxicity associated with osthole treatment.

\section{Tissue staining}

All harvested tissues were fixed in 10\% formaldehyde and embedded in formalin. Tissues were sectioned at 5- $\mu \mathrm{m}$ thickness. Heart, liver and kidney tissues were stained with hematoxylin and eosin (H\&E). Tumor tissue sections were deparaffinized, rehydrated and incubated with primarily Ki-67, Bcl-2, Cleaved-caspase 3, MDM2 and CDC2 antibodies. HRP-conjugated secondary antibodies and diaminobenzidine (DAB) were used for detection.

\section{Statistical analysis}

Data shown as mean \pm SEM with $n \geq 3$ independent samples. Statistical analysis was performed with GraphPad Prism 5.0 software (San Diego, CA, USA). One-way ANOVA followed by Dunnett's post hoc test was used for comparing more than two groups of data, and one-way ANOVA, non-parametric Kruskal-Wallis test, followed by Dunn's post hoc test was used when comparing multiple independent groups. All other results were analyzed using t-test. Values of $P<0.05$ were considered statistically significant. Post hoc tests were run only if $\mathrm{F}$ achieved $P<0.05$ and there was no significant variance in homogeneity.

\section{Results}

\section{Osthole effectively suppresses cell viability by inducing} apoptosis in human TNBC cells

Osthole has been reported to exhibit inhibitory activity in a number of human cancers. To investigate whether osthole exhibits similar inhibitory role in breast cancer cells, we first assessed the viability of human breast cancer cells following exposure to osthole. TNBC cells (MDA-MB-231, BT-549, and MDA-MB-468 cells) and non-TNBC cells (MCF-7) were challenged with increasing concentrations of osthole, and the numbers of viable cells were measured by the MTT assay. Our results show that exposure of these breast cancer cells to osthole reduced viability of cells in a dose-dependent manner, at $24 \mathrm{~h}, 48 \mathrm{~h}$, and $72 \mathrm{~h}$ (Fig. 1B, C, and Additional file 1: Figure $\mathrm{S} 1 \mathrm{~A})$. The $\mathrm{IC}_{50}$ values were found to be 129.4 , 106.2, 105.4, and $168 \mu \mathrm{M}$ at $24 \mathrm{~h}$ for MDA-MB-231, BT-549, MDA-MB-468, and MCF-7, respectively. Longer-term exposure for $48 \mathrm{~h}$ or $72 \mathrm{~h}$ appeared to be more effective as can be seen by reduced IC50 values. In addition, osthole was less cytotoxic and had higher $\mathrm{IC}_{50}$ values in MCF-7 cells than in TNBC cells.

Reduced viability in TNBC cells following osthole exposure prompted us to determine whether osthole was inducing apoptosis. Based on our results showing that BT-549 

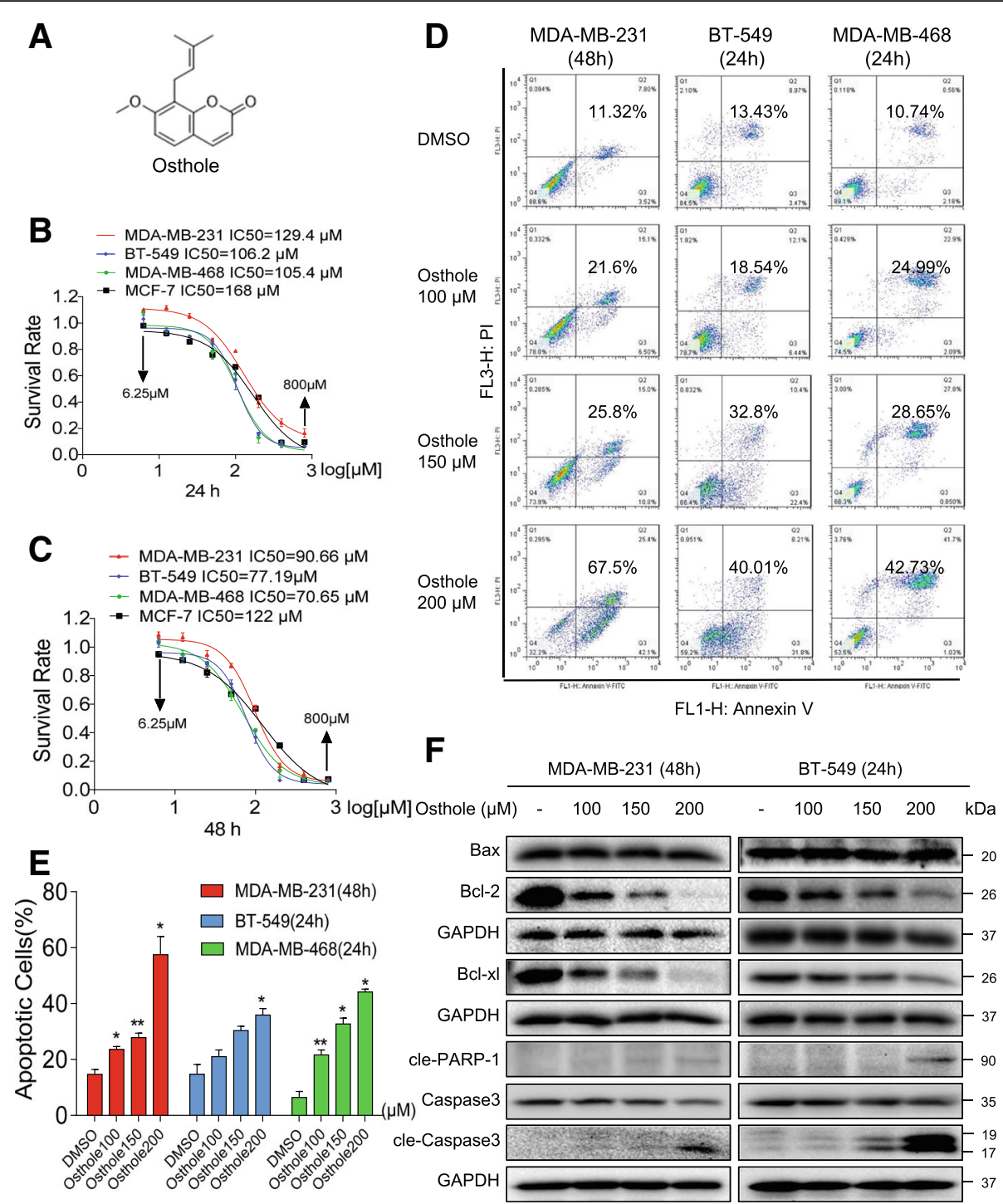

Fig. 1 Osthole inhibits cell growth and induces apoptosis in TNBC cells. a Chemical structure of osthole. b, c The effects of osthole on the viability of human TNBC cells. MDA-MB-231, BT-549, MDA-MB-468, and MCF-7 cells were challenged with increasing concentrations of osthole. Cell viability was determined by MTT assay and the $\mathrm{IC}_{50}$ values at $24 \mathrm{~h}(\mathbf{b})$ and $48 \mathrm{~h}$ (c) were calculated. $\mathbf{d}$ Induction of apoptosis in TNBC cells as determined by annexin V/PI staining following exposure to osthole. e Quantification of annexin V/PI staining showing the percentage of apoptotic cells following osthole challenge ${ }^{*} P<0.05$, ${ }^{*} P<0.01$ and ${ }^{*}{ }^{*} P<0.001$ compared to DMSO control]. f MDA-MB-231 and BT-549 cells were challenged with osthole for $48 \mathrm{~h}$ or $24 \mathrm{~h}$, respectively. Cell lysates were then subjected to assessment of apoptosis-related proteins by western blot. GAPDH was used as internal control. Data representative of 3 independent experiments

cells are more sensitive to osthole compared to MDAMB-231, we selected $48 \mathrm{~h}$ timepoint for MDA-MB-231 and $24 \mathrm{~h}$ for BT-549 to assess apoptosis. Osthole exposure at these timepoints showed nuclear morphological changes illustrative of apoptotic cell death, including nuclear condensation and fragmentation (Additional file 1: Figure S1B). Staining of cells with annexin V/PI showed induction of cellular apoptosis in all three TNBC lines after osthole exposure (Fig. 1d and e). We confirmed these findings by detecting apoptosis-related proteins in TNBC cells. Our results show that osthole decreased Bcl-2 and
Bcl-xl (Fig. 1f). In addition, Bax was unaltered in MDA-MB-231 and BT-549. Decreased Bcl-2: Bax ratio signified induction of apoptosis in cells. Figure if also showed that osthole treatment increased the levels of cleaved PARP1 and cleaved caspase 3 in TNBC cells.

\section{Osthole causes cell cycle arrest in TNBC cells}

We next determined the effect of osthole on growth of TNBC cells. We treated the cells with increasing concentrations of osthole and assessed cell cycle phase distribution. Osthole induces G2/M cell cycle arrest in MDA-MB-231 as 
well as BT-549 (Fig. 2a-c). We observed accumulation of cells in the G2/M phase upon $150 \mu \mathrm{M}$ osthole exposure in MDA-MB-231 and BT-549 cells. Greatest accumulation in $\mathrm{G} 2 / \mathrm{M}$ phase was noted with $200 \mu \mathrm{M}$ osthole. G2/M is an important DNA damage checkpoint and involves a number of regulatory proteins. Key among them are MDM2, Cyclin B1, and CDC2. We assessed the level of these proteins in TNBC cells exposed to osthole and show that osthole causes a decrease in the levels of MDM-2, Cyclin B1, and CDC2 (Fig. 2d). Although the $\mathrm{Tyr}^{15}$ phosphorylation of $\mathrm{CDC} 2$ is also important for the $\mathrm{G} 2 / \mathrm{M}$ phase, we found that osthole induced the remarkable decrease of cdc2 expression. Together, these data reveal that osthole-induced reduced viability of TNBC involves G2/M phase arrest and apoptotic cell death.

\section{Proteomic identification of osthole binding proteins}

To identify the mechanism and targets underlying the inhibitory osthole activity, we screened for potential osthole binding proteins. To do this, we first generated biotinylated osthole (Bio-osthole). Osthole does not contain modifiable sites such as hydroxyl $(-\mathrm{OH})$ and carboxyl $(-\mathrm{COOH})$, thus we added hydroxyl at the 7 - or 8-position isoprenyl ends of osthole to link biotin and obtain biotinylated osthole (Fig. 3a). To ensure that the generated Bio-osthole retained its inhibitory activity in TNBC, we assessed cell viability and compared the

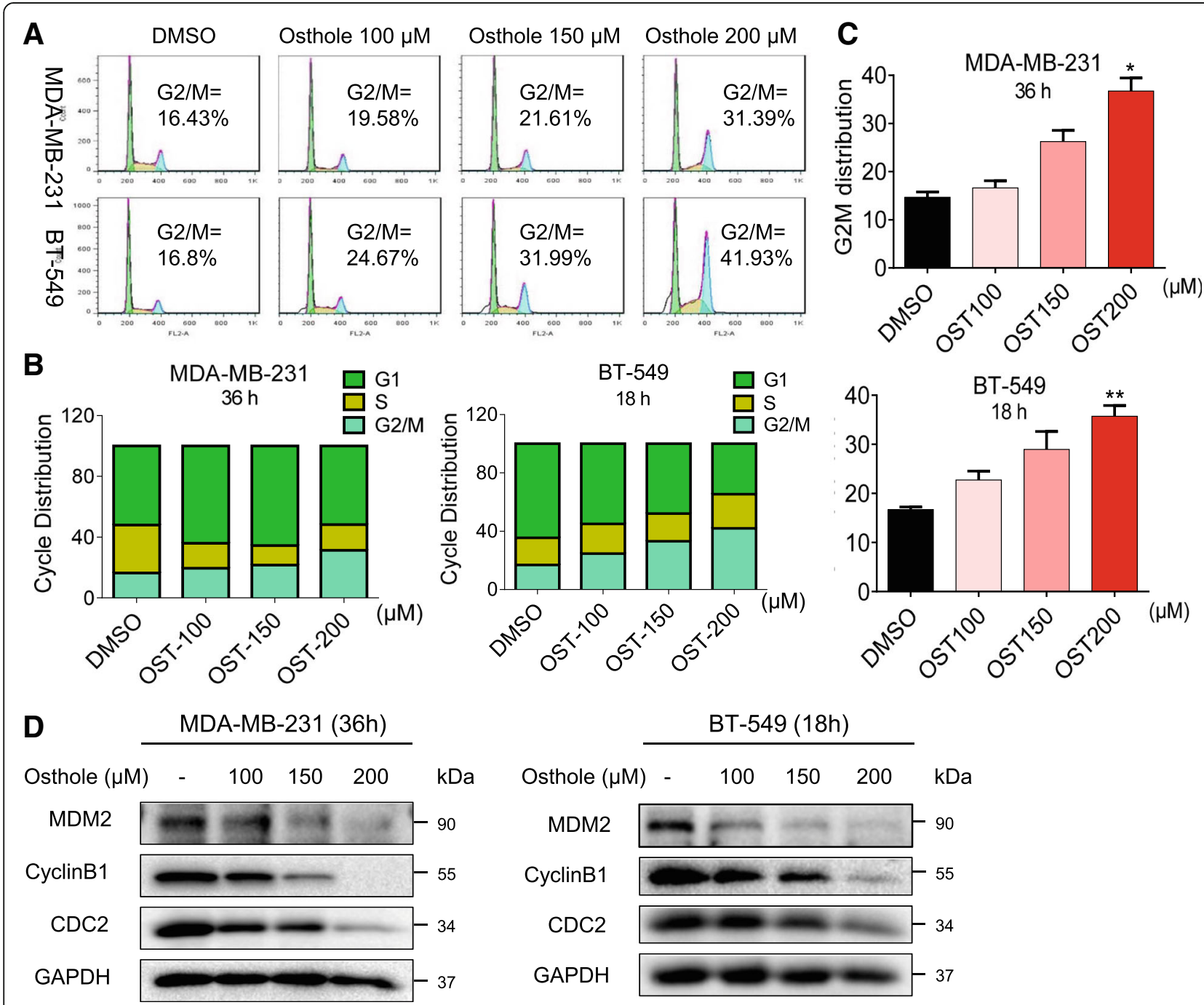

Fig. 2 Osthole induces cell cycle arrest in TNBC cells. a Induction of cycle arrest in TNBC cells was determined by PI staining and flow cytometry. Cells were exposed to osthole for $36 \mathrm{~h}$ (MDA-MB-231) or $18 \mathrm{~h}$ (BT-549). b The distribution of cell cycle phase in cells challenged with osthole. $\mathbf{c}$ Representative histograms from flow cytometric analysis in the three TNBC cells treated with osthole ${ }^{*} P<0.05$ and ${ }^{* *} \mathrm{P}<0.01$ compared to DMSO control]. d MDA-MB-231 and BT-549 cells were exposed to $200 \mu \mathrm{M}$ osthole for $36 \mathrm{~h}$ and $18 \mathrm{~h}$, respectively. Levels of G2/M cell cycle-related proteins MDM-2, Cyclin B1 and CDC2 were determined by western blot. GAPDH was used as internal control. Data representative of 3 independent experiments 
A<smiles>CCOc1ccc([O-])cc1CC=C(C)COC(=O)CCCCC1SCC2NC(=O)NC21</smiles>

\section{B}
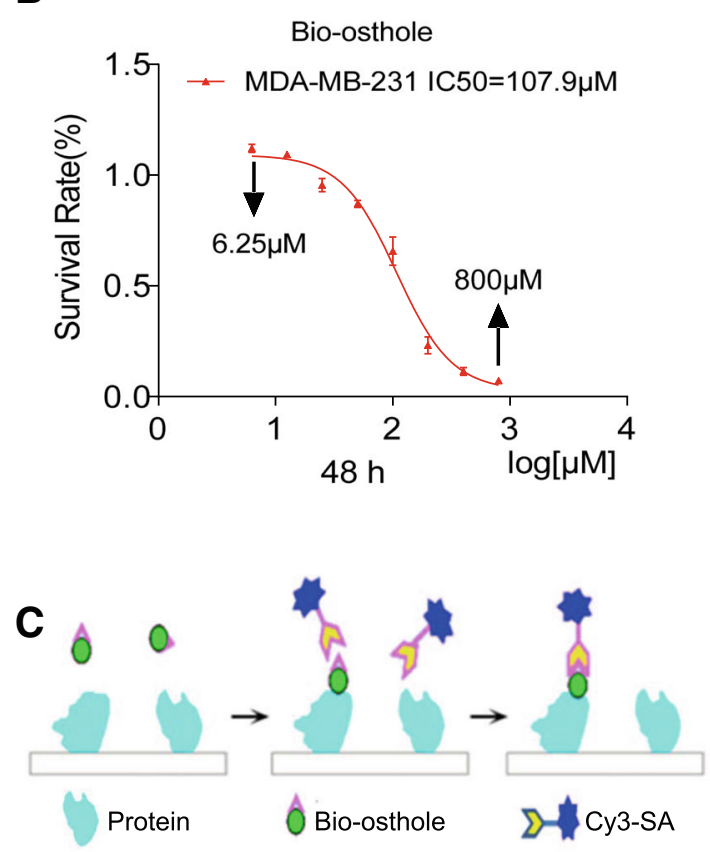

Bio-osthole

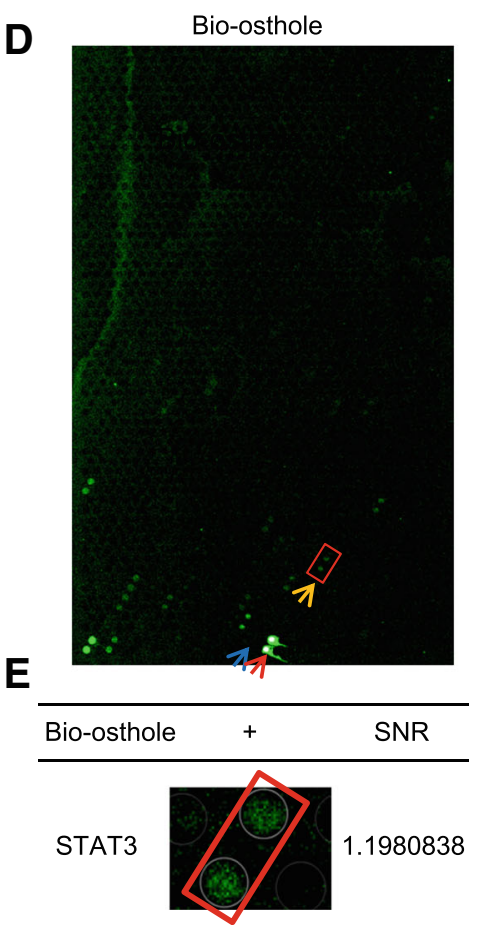

Fig. 3 Identification of osthole binding proteins. a Chemical structure of osthole intermediate and Biotin-labeled osthole. b Viability of MDA-MB231 cells exposed to biotin-labeled osthole as determined by MTT assay. c A schematic illustrating the steps for identifying Bio-osthole binding to proteins fabricated on a microarray. $\mathbf{d}$ Representative image of an experimental microarray [Blue = negative control, red = positive control, yellow = positive spot]. e Magnified image of Bio-osthole binding to recombinant STAT3 protein spot on the microarray Signal to noise ratio (SNR) value is shown

results to osthole. We found that the $\mathrm{IC}_{50}$ values of Bio-osthole in MDA-MB-231 cells was $107.9 \mu \mathrm{M}$, similar closer to the $\mathrm{IC}_{50}(90.66 \mu \mathrm{M})$ of osthole (Fig. 3b). Therefore, Bio-osthole was selected for subsequent protein microarray study. We then used a human proteomic microarray containing 19,394 affinity purified N-terminal GST tagged proteins and covering approximately $75 \%$ of the human proteome with Bio-osthole. Briefly, microarrays were probed with Bio-osthole and binding was detected with a Cy3-conjugated streptavidin (Cy3-SA) (Fig. 3c). We then calculated the signal to noise ratio (SNR) for each spot, which was defined as the ratio of median foreground minus median background. We found 199 osthole binding proteins (SNR maximum 1.6178193) (Fig. 3d). Of these proteins, we found STAT3 (SNR 1.1980838) (Fig. 3e) to be an osthole binding protein. Recent studies have demonstrated that STAT3 is abnormally activated in a variety of malignancies, including TNBC. In addition, inhibition of STAT3 can promote apoptosis in human cancers. Taken together, we speculated that STAT3 might be the potential target protein of osthole in generating the inhibitory growth effect in TNBC cells.

\section{Osthole inhibits constitutive and interleukin-6 (IL-6)- induced STAT3 activity}

As our analysis of osthole binding proteins revealed STAT3 as a candidate, we assessed the activity of STAT3 in TNBC cells. We found high basal levels of STAT3 phosphorylation (p-STAT3) at tyrosine 705 in in MDA-MB-231 and BT-549 cell lines (Fig. $4 \mathrm{a}$ and $\mathrm{b}$ ). Exposure of cells to osthole reduced the levels of P-STAT3 but not total STAT3 proteins in both a time- and dose-dependent manner (Fig. $4 \mathrm{a}$ and b). These findings suggest that osthole may inhibit the activity of STAT3 through direct binding.

Interleukin-6 (IL-6) is known to stimulate STAT3 phosphorylation on tyrosine Tyr705 in many cancer 
A

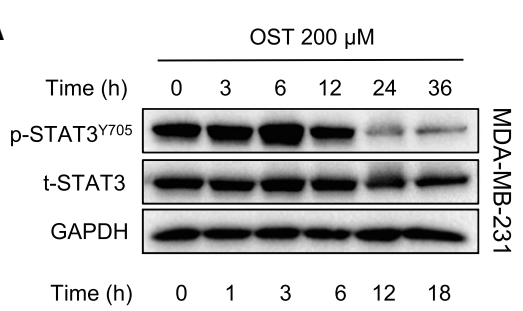

p-STAT3 ${ }^{\text {Y705 }}$

t-STAT3

GAPDH

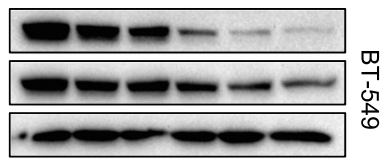

D

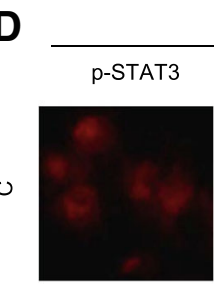

MDA-MB-231
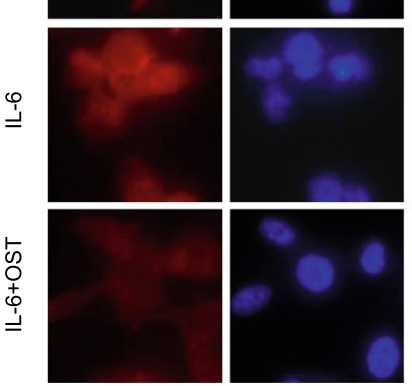

DAPI
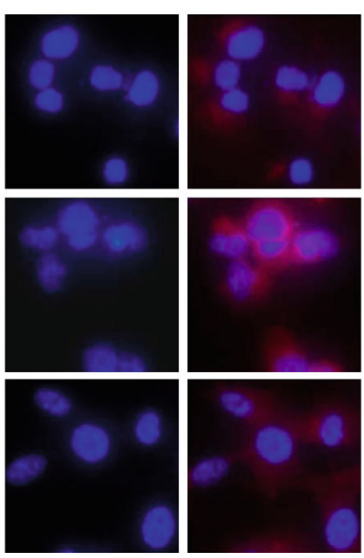

B

C

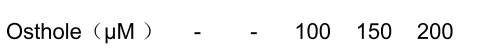

$\mathrm{IL}-6(50 \mathrm{ng} / \mathrm{ml}) \quad-\quad+\quad+\quad+\quad+$

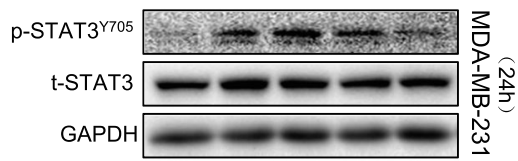

p-STAT3 ${ }^{\text {Y705 }}$

t-STAT3

GAPDH

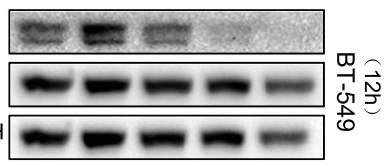

E

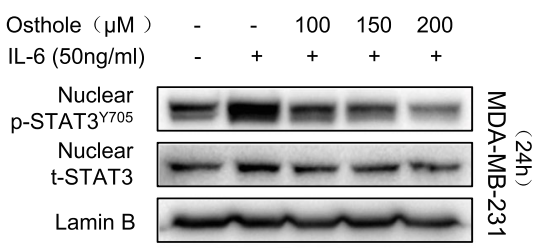

Fig. 4 Osthole inhibits STAT3 phosphorylation in TNBC cells. a MDA-MB-231 and BT-549 cells were treated with $200 \mu$ M osthole for the indicated times, and levels of P-STAT3 were determined by Western blot analysis. GAPDH and STAT3 were used as internal control. b MDA-MB-231 and BT549 cells were exposed to osthole at indicated concentrations for $24 \mathrm{~h}$ or $12 \mathrm{~h}$, respectively. P-STAT3 levels were determined by immunoblotting. GAPDH and STAT3 were used as internal control. c Cells were pretreated with $200 \mu \mathrm{M}$ osthole for $24 \mathrm{~h}$ (MDA-MB-231) or 12 h (BT-549) and then stimulated with IL-6 $(50 \mathrm{ng} / \mathrm{mL})$ for 30 mins. STAT3 phosphorylation was determined by western blot. $\mathbf{d}$ Immunofluorescence staining of cells showing distribution of P-STAT3 (red) in MDA-MB-231 cells. DAPI was used as counter stain. e MDA-MB-231 cells were pretreated with osthole for $24 \mathrm{~h}$ before exposure to IL-6 $(50 \mathrm{ng} / \mathrm{mL})$ for $30 \mathrm{~min}$. Nuclear extracts were subjected to P-STAT3 and STAT3 immunoblotting. Lamin B was used as loading control

cells. We performed western blotting to determine whether osthole is able to inhibit IL-6-mediated phosphorylation of STAT3. Indeed, osthole inhibits p-STAT3 induced by IL-6 in a dose-dependent manner (Fig. 4c). This inhibition can also be appreciated by immunofluorescence staining of cells with p-STAT3 antibody following IL-6 exposure (Fig. 4d). Furthermore, nuclear extracts prepared from cells show reduced levels of nuclear STAT3 in MDA-MB-231 cells exposed to IL-6 and osthole (Fig. 4e). These results show that osthole effectively prevents the activation and nuclear translocation of STAT3.

\section{STAT3 overexpression rescued osthole-mediated cytotoxic effects in MDA-MB-231 cells}

We next confirmed the involvement of STAT3 in osthole-induced cytotoxic effects by overexpressing STAT3. Overexpression of STAT3 was utilized to enhance the level of phosphorylated STAT3. We transfected cells with STAT3 expressing plasmid to increase STAT3 and p-STAT3 levels in MDA-MB-231 cells (Fig. 5a and b). Our results show that overexpression of STAT3 reversed osthole-induced apoptosis and cell G2/M cycle arrest in MDA-MB-231 cells (Fig. 5c-e). These findings demonstrate that the inhibitory activity of osthole in TNBC cells is, at least partly, mediated through the inhibition of STAT3.

\section{Osthole suppressed tumor growth and STAT3} phosphorylation of TNBC cells in vivo

Our final objective was to determine whether osthole inhibits the growth of TNBC cells in vivo and whether this inhibition is also mediated through STAT3. We utilized MDA-MB-231 breast cancer cell xenografts in nude mice for these studies. We treated the mice with osthole by intraperitoneal injections at two different doses, 100 or 200 


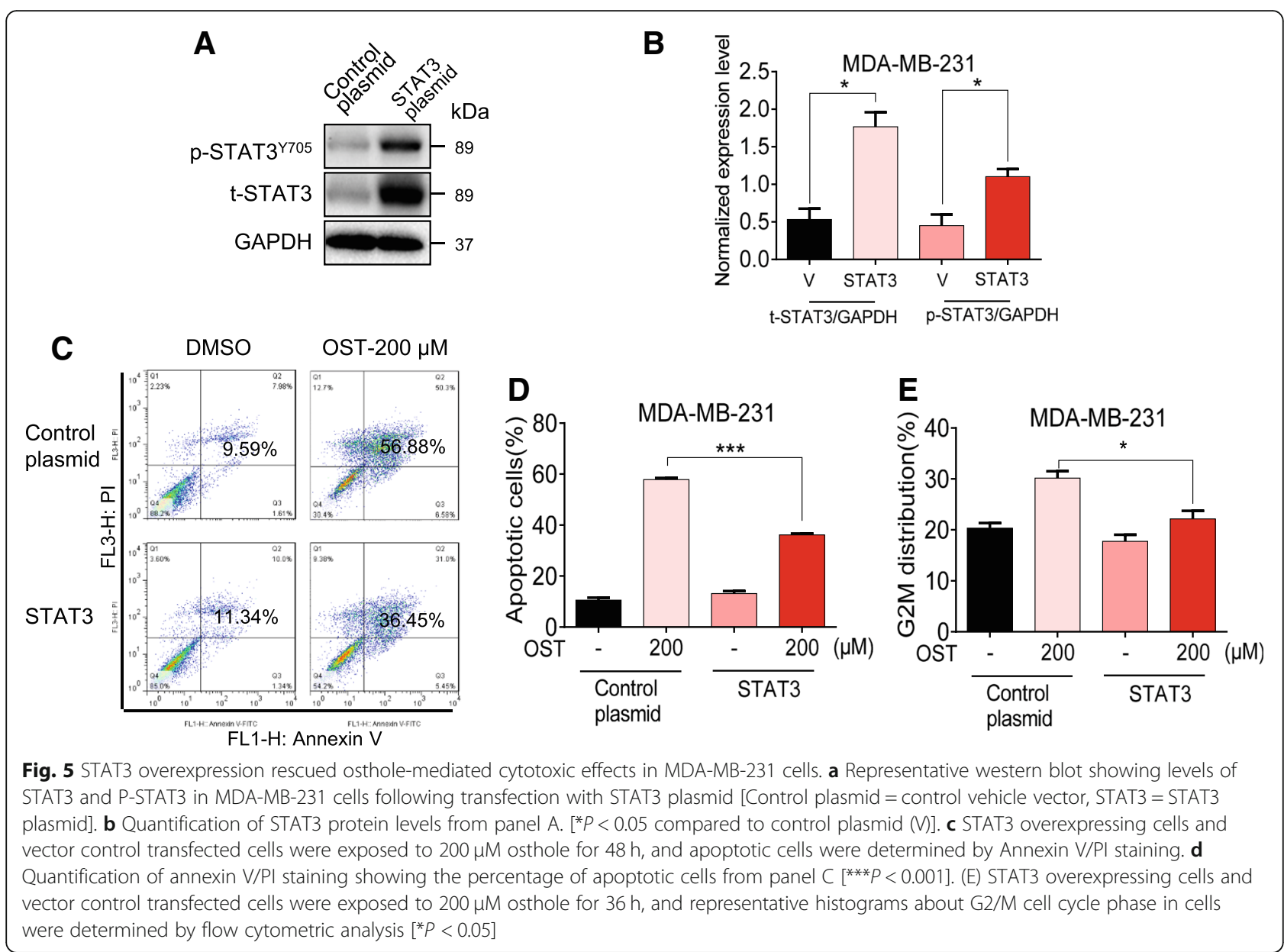

$\mathrm{mg} / \mathrm{kg}$. As shown in Fig. 6a-c, treatment with osthole resulted in a significant reduction in both tumor volume and weight compared to the vehicle group. We also noted that the difference of the size of tumors in the control group is relatively big, while the tumor sizes are statistically significant when comparing the control group with osthole-treated group. It is important to note that two mice in the osthole group had no detectable and measurable tumor after the treatment. No significant changes in body weights were noted in any of the experimental groups (Additional file 1: Figure S2A). H\&E staining analyses of heart, liver and kidney did not show any toxicity associated with osthole treatment (Additional file 1: Figure S2B).

We then measured the levels of STAT3 in lysates prepared from tumor specimens. Osthole treatment at either 100 or $200 \mathrm{mg} / \mathrm{kg}$ reduced the levels of p-STAT3 without altering the levels of total STAT3 (Fig. 6d). Immunohistochemical staining for Ki67 and Bcl2 showed reduced levels of tumor proliferation and growth in osthole-treated mice (Fig. 6e). In addition, levels of cleaved caspase- 3 were increased as evident by increased immunoreactivity. We also observed decreased levels of $\mathrm{G} 2 / \mathrm{M}$ proteins MDM2 and $\mathrm{CDC} 2$ in tumor specimens from mice treated with osthole (Fig. 6e).
These results indicate active apoptotic cell death and cell cycle inhibition in tumors treated with osthole. Collectively, our in vivo studies confirm the cytotoxic effects and mechanisms of osthole that we found in our culture studies.

\section{Discussion}

In present study, we found that osthole inhibited the growth of TNBC cells by inducing cell cycle arrest apoptosis. Similarly, osthole treatment of mice bearing MDA-MB-231 TNBC cells showed reduced tumor growth and increased cell apoptosis. We also discovered that osthole mediates these beneficial inhibitory effects in TNBC cells through the suppression of STAT3. Specifically, we demonstrate that osthole binds to and inhibits the phosphorylation of STAT3, thus inhibiting its nuclear translocation. Collectively, these results suggest osthole has potential as a promising candidate for the treatment of TNBC.

A recent in vitro study on two invasive mammary carcinoma cell lines, MDA-MB-231 and 4 T1 cells, showed that osthole inhibited cell proliferation when used in combination with platycodin D [16]. Platycodin D is a triterpene saponin and together with osthole reduced transforming growth factor- $\beta$ receptor signaling in breast cancer cells. It should be 


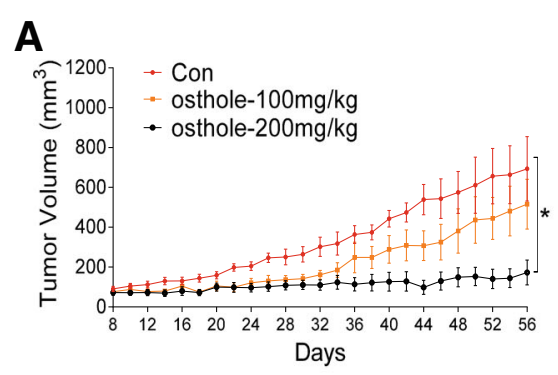

\section{B}

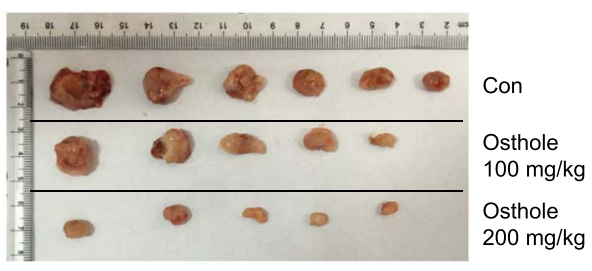

\section{C}
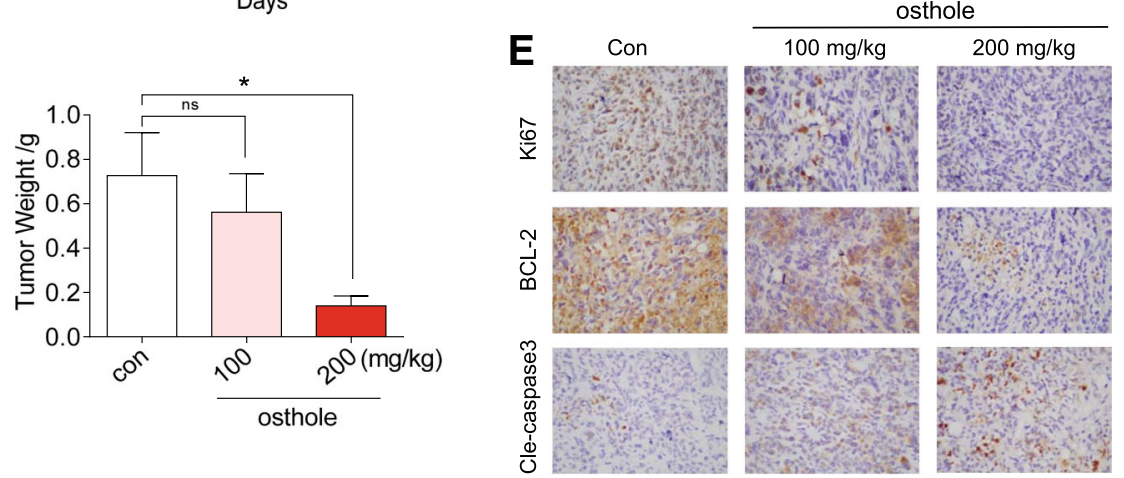

D
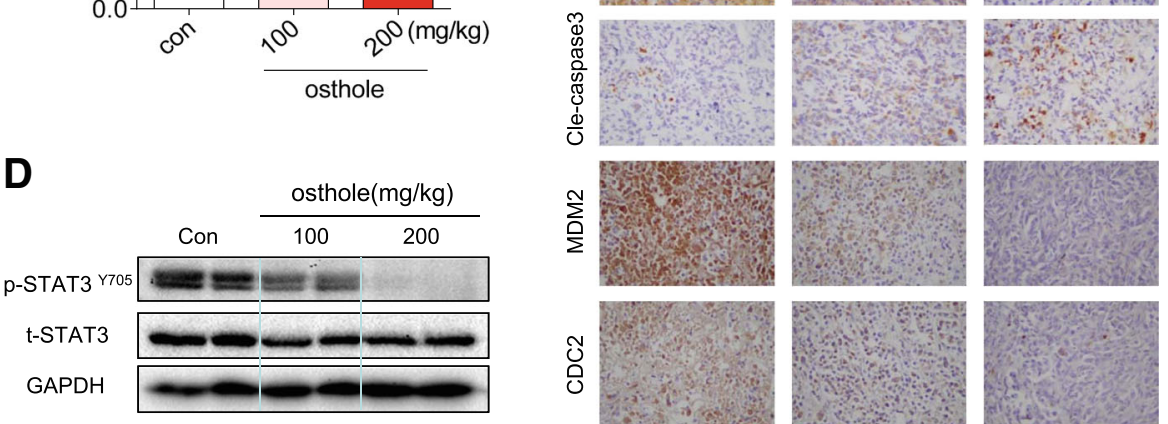

Fig. 6 Osthole inhibits MDA-MB-231 xenograft growth in vivo. a Tumor volume in vehicle- and osthole-treated mice. MDA-MB-231 cells were injected in the flanks of mice and tumors were allowed to develop for approximately $8 \mathrm{~d}\left(50-150 \mathrm{~mm}^{3}\right)$. Mice bearing MDA-MB-231 xenografts received osthole at 100 or $200 \mathrm{mg} / \mathrm{kg}$ interperitoneally [ $\left.{ }^{*} P<0.05\right]$ ]. b Images of resected tumor tissues at day 48 . Two mice (one in $100 \mathrm{mg} / \mathrm{kg}$ osthole group and the other in $200 \mathrm{mg} / \mathrm{kg}$ osthole group did not have a visible tumor after $48 \mathrm{~d}$ treatment. c Tumor weights determined on day $48\left[{ }^{*} P<0.05\right.$ compared to vehicle control]. $\mathbf{d}$ Western blot analysis of P-STAT3 levels in resected tumor specimens. GAPDH was used as loading control. e Immunohistochemical staining of tumor sections for cell proliferation marker Ki-67, apoptosis markers Bcl-2 and cleaved caspase-3, and cell cycle markers MDM2, and CDC2. Representative images are shown

noted that this suppression of signaling was seen in the combination treatment and it is not clear whether osthole along inhibits the pathway. Using a proteomic microarray containing 19,394 proteins, we identified 199 candidate targets to which osthole may bind. One of these candidate binding proteins was STAT3. STAT3 is a member of STAT transcription factors that mediate many aspects of immunity, proliferation, apoptosis and differentiation [17, 18]. This wide range of cellular activities may explain the spectrum of beneficial effects seen with osthole in a variety of disease models. STAT3 is found constitutively phosphorylated in a number of human cancer cell lines and primary tumors [19]. Evidence also suggests that constitutive activation of STAT3 is a point of convergence for malignant transformation at several levels [20], including transformation, proliferation, invasion, and metastasis [21-23]. STAT3 also has been reported to be constitutively active in TNBC [21, 24]. Although there is no difference in the expression levels of STAT3 in ER+, HER2, and TNBC breast cancer subtypes, active and phosphorylated STAT3 has been shown to be restricted to TNBC $[25,26]$. Studies have shown that STAT3 signaling is critical for cell survival in TNBC [26-28].

Tumor cells which lack STAT activation are more tolerant to small molecular inhibitors which block STAT3 signal pathway [29-31]. Studies using normal mouse fibroblasts showed that blocking STAT3 signaling causes growth arrest but not apoptosis, suggesting that disruption of STAT3 pathway may not be grossly toxic [32]. However, a large number of malignant transformations with associated constitutive STAT3 activation have been reported [19, 33]. Studies have also shown that the suppression of constitutively active STAT3 leads to growth inhibition and apoptosis in tumor cell lines as well as in xenograft models [24, 34, 35]. Similarly, we found that osthole decreased phosphorylated STAT3 levels in vitro and in vivo. Therefore, STAT3 protein modulation may be an important aspect of the anti-tumor activity of osthole. Moreover, treatment with osthole significantly 
reduced the levels of phosphorylated STAT3 induced by IL-6 suggesting that osthole selectively inhibits STAT3 phosphorylation. These findings offer the potential for preferential tumor cell killing and make STAT3 an attractive and promising target for therapeutic intervention in human cancer.

\section{Conclusions}

In conclusion, we have identified the anti-tumor activity of osthole against TNBC cells and the potential underlying mechanisms. We found that osthole induced apoptosis and cell cycle arrest in TNBC cells through inhibition of STAT3 phosphorylation and nuclear translocation. This inhibitory activity is partly rescued by STAT3 overexpression. Owing to this inhibitory activity on STAT3 phosphorylation, osthole prevented the proliferatio of TNBC implanted in mice and induced apoptosis. Taken together, our findings show that osthole is a promising candidate for TNBC therapy. Moreover, our results indicate that STAT3 may be targeted for the development of novel anti-TNBC drugs.

\section{Additional file}

Additional file 1: Figure S1. showed nuclear morphology of TNBC cells exposed to osthole and Figure $\mathbf{5 2}$. showed no toxicity in mice administrated with osthole. (PDF $195 \mathrm{~kb}$ )

\section{Abbreviations}

Cy3-SA: Cy3-conjugated streptavidin; ER: estrogen receptor; HER2: human epidermal growth factor receptor 2; IL-6: interleukin-6; PR: progesterone receptor; SNR: signal to noise ratio; STAT3: signal transducer and activator of transcription 3; TNBC: triple-negative breast cancer

\section{Acknowledgements}

We thank Dr. Zia Ali Khan from University of Ontario (London, Canada) for editing the language of this manuscript.

\section{Funding}

The work was supported by National Natural Science Foundation of China (81622043), Natural Science Foundation of Zhejiang Province (LY16H160050, LY17H160055, LY17H160050, and LYl6H160050), Zhejiang Medical and Health Science and Technology Project (2019RC204), and Wenzhou Science and Technology Project (Y20170176).

\section{Availability of data and materials}

All data generated or analysed during this study are included in this published article and its supplementary information file.

\section{Authors' contributions}

$X D, C Y, Y Z, C Z$, and $Y X$ performed the research; $G L, X Z$, and $O W$ designed the research study; $G G$, and $C Z$ contributed essential reagents or tools; G.L, $X D$, and $G G$ analyzed the data; $G L, X D$, and $X Z$ wrote the paper. All authors read and approved the final manuscript.

\section{Ethics approval and consent to participate}

All animal studies were performed with an approved protocol by the Institutional Animal Care and Use Committee of Wenzhou Medical University.

\section{Consent for publication}

Not applicable.

\section{Competing interests}

The authors declare that they have no competing interests.

\section{Publisher's Note}

Springer Nature remains neutral with regard to jurisdictional claims in published maps and institutional affiliations.

\section{Author details}

${ }^{1}$ Chemical Biology Research Center, School of Pharmaceutical Sciences, Wenzhou Medical University, Wenzhou 325035, Zhejiang, China. ${ }^{2}$ Department of Surgical Oncology, the First Affiliated Hospital of Wenzhou Medical University, Wenzhou 325035, Zhejiang, China. ${ }^{3}$ Department of dermatology, the First Affiliated Hospital of Wenzhou Medical University, Wenzhou 325035, Zhejiang, China.

Received: 5 September 2018 Accepted: 4 December 2018 Published online: 22 December 2018

\section{References}

1. Shi Y, Jin J, Ji W, Guan X. Therapeutic landscape in mutational triple negative breast cancer. Mol Cancer. 2018;17(1):99.

2. Dent R, Trudeau M, Pritchard KI, Hanna WM, Kahn HK, Sawka CA, Lickley LA, Rawlinson E, Sun P, Narod SA. Triple-negative breast cancer: clinical features and patterns of recurrence. Clin Cancer Res. 2007;13(15 Pt 1):4429-34.

3. Tomao F, Papa A, Zaccarelli E, Rossi L, Caruso D, Minozzi M, Vici P, Frati L, Tomao S. Triple-negative breast cancer: new perspectives for targeted therapies. OncoTargets and therapy. 2015:8:177-93.

4. Wein L, Luen SJ, Savas P, Salgado R, Loi S. Checkpoint blockade in the treatment of breast cancer: current status and future directions. Br J Cancer. 2018;119(1):4-11.

5. Carey LA, Dees EC, Samyer L, Gatti L, Moore DT, Collichio F, Ollila DW, Sartor Cl, Graham ML, Perou CM. The triple negative paradox: primary tumor chemosensitivity of breast cancer subtypes. Clin Cancer Res. 2007;13(8):2329-34.

6. Emens LA. Breast cancer immunotherapy: facts and hopes. Clin Cancer Res. 2018;24(3):511-20.

7. Matsuda $\mathrm{H}$, Tomohiro N, Ido $\mathrm{Y}$, Kubo M. Anti-allergic effects of cnidii monnieri fructus (dried fruits of cnidium monnieri) and its major component, osthol. Biol Pharm Bull. 2002;25(6):809-12.

8. Liang HJ, Suk FM, Wang CK, Hung LF, Liu DZ, Chen NQ, Chen YC, Chang CC, Liang YC. Osthole, a potential antidiabetic agent, alleviates hyperglycemia in db/db mice. Chem Biol Interact. 2009;181(3):309-15.

9. Cai Y, Sun W, Zhang XX, Lin YD, Chen H, Li H. Osthole prevents acetaminopheninduced liver injury in mice. Acta Pharmacol Sin. 2018:39(1):74-84.

10. Okamoto T, Kobayashi T, Yoshida S. Chemical aspects of coumarin compounds for the prevention of hepatocellular carcinomas. Curr Med Chem Anticancer Agents. 2005;5(1):47-51.

11. Wang H, Jia XH, Chen JR, Wang JY, Li YJ. Osthole shows the potential to overcome $\mathrm{p}$-glycoproteinmediated multidrug resistance in human myelogenous leukemia k562/adm cells by inhibiting the pi3k/akt signaling pathway. Oncol Rep. 2016;35(6):3659-68.

12. $\mathrm{Xu} X$, Liu $X$, Zhang $Y$. Osthole inhibits gastric cancer cell proliferation through regulation of pi3k/akt. PLoS One. 2018;13(3):e0193449.

13. Kao SJ, Su JL, Chen CK, Yu MC, Bai KJ, Chang JH, Bien MY, Yang SF, Chien $\mathrm{MH}$. Osthole inhibits the invasive ability of human lung adenocarcinoma cells via suppression of nf-kappab-mediated matrix metalloproteinase-9 expression. Toxicol Appl Pharmacol. 2012;261(1):105-15.

14. Wu C, Sun Z, Guo B, Ye Y, Han X, Qin Y, Liu S. Osthole inhibits bone metastasis of breast cancer. Oncotarget. 2017;8(35):58480-93.

15. Wang L, Peng Y, Shi K, Wang H, Lu J, Li Y, Ma C. Osthole inhibits proliferation of human breast cancer cells by inducing cell cycle arrest and apoptosis. J Biomed Res. 2015;29(2):132-8.

16. Ye Y, Han X, Guo B, Sun Z, Liu S. Combination treatment with platycodin d and osthole inhibits cell proliferation and invasion in mammary carcinoma cell lines. Environ Toxicol Pharmacol. 2013;36(1):115-24.

17. Darnell JE Jr, Kerr IM, Stark GR. Jak-stat pathways and transcriptional activation in response to ifns and other extracellular signaling proteins. Science. 1994:264(5164):1415-21.

18. Yu H, Pardoll D, Jove R. Stats in cancer inflammation and immunity: a leading role for stat3. Nat Rev Cancer. 2009;9(11):798-809.

19. Yu H, Jove R. The stats of cancer--new molecular targets come of age. Nat Rev Cancer. 2004;4(2):97-105.

20. Xie TX, Wei D, Liu M, Gao AC, Ali-Osman F, Sawaya R, Huang S. Stat3 activation regulates the expression of matrix metalloproteinase-2 and tumor invasion and metastasis. Oncogene. 2004;23(20):3550-60. 
21. Xiong A, Yang Z, Shen Y, Zhou J, Shen Q. Transcription factor stat3 as a novel molecular target for cancer prevention. Cancers. 2014;6(2):926-57.

22. Carpenter RL, Lo HW. Stat 3 target genes relevant to human cancers. Cancers. 2014:6(2):897-925.

23. Kamran MZ, Patil P, Gude RP. Role of stat3 in cancer metastasis and translational advances. BioMed Rese Int. 2013;2013:421821.

24. Deng XS, Wang S, Deng A, Liu B, Edgerton SM, Lind SE, Wahdan-Alaswad R, Thor AD. Metformin targets stat 3 to inhibit cell growth and induce apoptosis in triple-negative breast cancers. Cell Cycle. 2012;11(2):367-76.

25. Walker SR, Nelson EA, Zou L, Chaudhury M, Signoretti S, Richardson A, Frank DA. Reciprocal effects of stat5 and stat3 in breast cancer. Mol Cancer Res. 2009;7(6):966-76.

26. Marotta LL, Almendro V, Marusyk A, Shipitsin M, Schemme J, Walker SR, Bloushtain-Qimron N, Kim JJ, Choudhury SA, Maruyama R, Wu Z, Gonen M, Mulvey LA, Bessarabova MO, Huh SJ, Silver SJ, Kim SY, Park SY, Lee HE, Anderson KS, Richardson AL, Nikolskaya T, Nikolsky Y, Liu XS, Root DE, Hahn WC, Frank DA, Polyak K. The jak2/stat3 signaling pathway is required for growth of cd44 (+) cd24 (-) stem cell-like breast cancer cells in human tumors. J Clin Invest. 2011;121(7):2723-35.

27. Zhang W, Yu W, Cai G, Zhu J, Zhang C, Li S, Guo J, Yin G, Chen C, Kong L. A new synthetic derivative of cryptotanshinone kyz3 as stat3 inhibitor for triple-negative breast cancer therapy. Cell Death Dis. 2018;9(11):1098.

28. He N, Kong Y, Lei X, Liu Y, Wang J, Xu C, Wang Y, Du L, Ji K, Wang Q, Li Z, Liu Q. Mscs inhibit tumor progression and enhance radiosensitivity of breast cancer cells by down-regulating stat3 signaling pathway. Cell Death Dis. 2018;9(10):1026.

29. Garcia R, Bowman TL, Niu G, Yu H, Minton S, Muro-Cacho CA, Cox CE, Falcone R, Fairclough R, Parsons S, Laudano A, Gazit A, Levitzki A, Kraker A, Jove R. Constitutive activation of stat3 by the src and jak tyrosine kinases participates in growth regulation of human breast carcinoma cells. Oncogene. 2001;20(20):2499-513.

30. Catlett-Falcone R, Landowski TH, Oshiro MM, Turkson J, Levitzki A, Savino R, Ciliberto G, Moscinski L, Fernandez-Luna JL, Nunez G, Dalton WS, Jove R. Constitutive activation of stat3 signaling confers resistance to apoptosis in human u266 myeloma cells. Immunity. 1999;10(1):105-15.

31. Donato NJ, Wu JY, Zhang L, Kantarjian H, Talpaz M. Down-regulation of interleukin-3/granulocyte-macrophage colony-stimulating factor receptor beta-chain in bcr-abl (+) human leukemic cells: association with loss of cytokine-mediated stat- 5 activation and protection from apoptosis after bcrabl inhibition. Blood. 2001;97(9):2846-53.

32. Sinibaldi D, Wharton W, Turkson J, Bowman T, Pledger WJ, Jove R. Induction of p21waf1/cip1 and cyclin d1 expression by the src oncoprotein in mouse fibroblasts: role of activated stat3 signaling. Oncogene. 2000;19(48):5419-27.

33. Buettner R, Mora $L B$, Jove R. Activated stat signaling in human tumors provides novel molecular targets for therapeutic intervention. Clin Cancer Res. 2002:8(4):945-54.

34. Gritsina G, Xiao F, O'Brien SW, Gabbasov R, Maglaty MA, Xu RH, Thapa RJ, Zhou Y, Nicolas E, Litwin S, Balachandran S, Sigal L, Huszar D, Connolly DC. Targeted blockade of jak/stat3 signaling inhibits ovarian carcinoma growth. Mol Cancer Ther. 2015;14(4):1035-47.

35. Yu H, Lee H, Herrmann A, Buettner R, Jove R. Revisiting stat3 signalling in cancer: new and unexpected biological functions. Nat Rev Cancer. 2014;14(11):736-46.

Ready to submit your research? Choose BMC and benefit from:

- fast, convenient online submission

- thorough peer review by experienced researchers in your field

- rapid publication on acceptance

- support for research data, including large and complex data types

- gold Open Access which fosters wider collaboration and increased citations

- maximum visibility for your research: over $100 \mathrm{M}$ website views per year

At BMC, research is always in progress.

Learn more biomedcentral.com/submissions 